\title{
Spectral Characterization of Difusse Par Irradiance under Tipuana Tipu Shading
}

\author{
Gonzalo GURREA-YSASI, Vicente BLANCA, Ana FITA, Jaime PROHENS, Inmaculada FITA, Adrián \\ RODRIGUEZ-BURRUEZO*
}

Instituto de Conservación y Mejora de la Agrodiversidad Valenciana (COMAV), Universitat Politècnica de València, Camino de Vera 14, 46022 Valencia, Spain

*corresponding author: adrodbur@doctor.upv.es

Bulletin UASVM Horticulture 75(1) / 2018

Print ISSN 1843-5262, Electronic ISSN 1843-536X

DOI:10.15835/buasvmcn-hort: 000917

\begin{abstract}
Tipa (Tipuana tipu) is a common tree in gardens and carparks, although the shading effect of its canopy must be still characterised to assess the decrease of temperature and quality of irradiance. This work is a preliminary study aimed to assess the effect of shading of tree canopies on the diffuse irradiance pattern received at the soil level in comparison to other conditions. The shade provided by a group of Tipa trees, located at the Universitat Politècnica de València (Valencia, Spain), was evaluated in this experiment and compared to cloudy days and direct sun. Photosynthetic Photon Flux Density (PPFD) and red/near infrared ratios were recorded with a portable spectrometer. Measurements were recorded in January and February 2017, at 10h, $13 \mathrm{~h}$ and $16 \mathrm{~h}$. Depending on the region of the spectrum and time of the day, PPFD values ranged from 0.05 to $0.42,0.40$ to 1.14 , and 0.94 to 3.90 $\mu \mathrm{mol} \cdot \mathrm{m}^{-2} \cdot \mathrm{s}^{-1}$, for Tipa shade, cloudy days and direct sun, respectively. The spectral analysis of PPFD in cloudy days revealed maximum values in the green region and minimum at near infrared region, while maximum PPFD for tipa shade was mostly found at near infrared, revealing higher importance of this spectral region compared to cloudy days.
\end{abstract}

Keywords: trees shading, infrared irradiance, photosynthetic photon flux

\section{Introduction}

Tipa, rosewood or yellow jacaranda (Tipuana tipu, fam. Fabaceae) is a tree from South America, very common in gardens, urban forestry and carparks because of its fast development and shading canopy (Burkhill, 1997). Nevertheless, the shading effect of the canopy must be still characterised to assess the decrease of temperature and quality of irradiance reaching the soil. This work is a preliminary study aimed to assess the effect of shading of Tipa canopy on the diffuse irradiation pattern received at the soil level in comparison to other conditions.

\section{Materials and methods}

A population of Tipa providing a continuous shading area, located in the gardens of the UPV Presidency (Valencia, Spain) was used in the present experiment to study the effect of Tipa canopy to modify the irradiance spectrum from sunlight. Three conditions were evaluated at 30 $\mathrm{cm}$ over ground level: i) Tipa shade, ii) cloudy days, and iii) direct sun exposure (control). Measurements were done in January $24^{\text {th }}$ and $25^{\text {th }}$ and February $3^{\text {rd }}$ and $14^{\text {th }} 2017$, at $10 \mathrm{~h}, 13 \mathrm{~h}$ and 16h. Photosynthetic Photon Flux Density (PPFD) and red/infrared ratios were recorded with an Asensetek handheld ALP-01 spectrometer (New Taipei City, Taiwan), covering a range of 380 to 780 nm wavelength spectrum.

\section{Results and discussion}

Total PPFD values differed considerably among the three studied conditions. Thus, original PAR (solar irradiance) was decreased to $33 \%$ by clouds and even more to $2.5 \%$ by Tipa canopy (Tab. 1), confirming the efficient shading effect of this species. Furthermore, the weakening effect 
Table 1. PPFD (total and different spectral regions) and red/near IR ratio values (mean \pm SD) corresponding to direct sun, cloudy days and Tipa shade conditions $(n=6)$

\begin{tabular}{cccc}
\hline & Direct sun & Cloudy & Tipa shade \\
\hline TOTAL PPFD $\left(\boldsymbol{\mu m o l} / \mathbf{m}^{2} \mathbf{s}\right)$ & $972.8 \pm 217.2$ & $310.40 \pm 133.03$ & $24.8 \pm 6.1$ \\
\hline PPFD IR $\left(\boldsymbol{\mu m o l} / \mathbf{m}^{2} \mathbf{s}\right)$ & $269.0 \pm 57.2$ & $77.38 \pm 36.87$ & $22.6 \pm 3.4$ \\
\hline PPFD R $\left(\boldsymbol{\mu m o l} / \mathbf{m}^{2} \mathbf{s}\right)$ & $358.2 \pm 78.1$ & $105.11 \pm 49.41$ & $6.3 \pm 1.7$ \\
\hline PPFD G $\left(\boldsymbol{\mu m o l} / \mathbf{m}^{2} \mathbf{s}\right)$ & $345.1 \pm 77.8$ & $107.87 \pm 47.31$ & $9.0 \pm 2.2$ \\
\hline PPFD B $\left(\boldsymbol{\mu m o l} / \mathbf{m}^{2} \mathbf{s}\right)$ & $269.5 \pm 61.4$ & $97.41 \pm 36.30$ & $9.5 \pm 2.3$ \\
\hline PPFD UV $\left(\boldsymbol{\mu m o l} / \mathbf{m}^{2} \mathbf{s}\right)$ & $23.8 \pm 5.4$ & $10.15 \pm 3.03$ & $1.4 \pm 0.4$ \\
\hline R/IR ratio & $1.34 \pm 0.01$ & $1.36 \pm 0.01$ & $0.28 \pm 0.03$ \\
\hline
\end{tabular}

was different depending on the spectral regions and shading conditions (i.e. the quality of the wavelength spectrum depended on the type of shade).

In this regard, similarly to other reports (Ge et al., 2010), the spectral analysis of PPFD revealed that clouds may decrease 2-3 fold this parameter in most spectral regions, showing a quantitative contribution of the different regions similar to that recorded from direct sun, i.e. red and green regions with the highest values, followed by blue region and to a lesser extent near IR and finally UV-C (Tab. 1). By contrast, regardless Tipa canopy decreased dramatically PPFD in all the spectral regions, this effect was lower for near IR. Consequently, under tipa shade, near IR was predominant, followed by green, blue and red regions and traces from UV-C (Tab. 1).

Our results indicate that Tipa canopy is considerably more efficient in blocking the whole
PPFD from sun irradiance than clouds, almost removing UV-C. Nevertheless, still a considerable amount of near IR component is present at ground level below its shade, probably due to diffuse irradiance as well as a lower efficiency of plant tissues in capturing photons from near IR compared to other regions (Jensen, 1980). Nevertheless, the efficiency of this species in weakening solar irradiance must still be compared to other trees.

\section{References}

1. Burkhil HM (1997). The useful plants of West Tropical Africa. Royal Botanic Gardens, Kew, UK, 3 (pp 857).

2. Ge S, Smith RG, Jacovides CP, Kramer MG, Carruthers RI (2010). Dynamics of photosynthetic photon flux density (PPFD) and estimates in coastal northern California. Theor. Appl. Climatol. 105: 107-118.

3. Jensen A (1980). Seasonal changes in near infrared reflectance ratio and standing crop biomass in a salt marsh community dominated by Halimione Portulacoides (L.) Aellen. New Phytol, 86: 57-67. 